\title{
The forkhead domain gene unc-130 generates chemosensory neuron diversity in C. elegans
}

\author{
Trina R. Sarafi-Reinach and Piali Sengupta ${ }^{1}$ \\ Department of Biology and Volen Center for Complex Systems, Brandeis University, Waltham, Massachusetts 02454, USA
}

\begin{abstract}
Caenorhabditis elegans responds to its complex chemical environment using a small number of chemosensory neurons. Each of these neurons exhibits a unique sensory response repertoire. The developmental mechanisms that generate this diversity of function are largely unknown. Many C. elegans chemosensory neurons, including the AWA and ASG neurons, arise as lineal sisters of an asymmetric division. Here we describe the gene unc-130, which plays a role in the generation of the AWA and ASG neurons. In unc-130 mutants, the ASG neurons adopt the fate of the AWA neurons. unc-130 encodes a member of the forkhead domain family of transcription factors, and is expressed in the precursors to AWA and ASG neurons. Misexpression of unc-130 in the AWA neurons is partly sufficient to repress the AWA fate, but not to promote ASG fate. unc-130 also plays a role in the development of additional chemosensory neurons. Our experiments show that the ASG neurons share a developmental default state in common with three types of olfactory neurons. We propose that distinct cell fates and hence diversity of function in the chemosensory neurons of $C$. elegans are generated in a hierarchical manner, utilizing both lineage-dependent and independent mechanisms.
\end{abstract}

[Keywords: Caenorhabditis elegans; chemosensory neuron; asymmetric division; forkhead]

Received July 5, 2000; revised version accepted August 15, 2000.

A central issue in developmental biology is understanding the mechanisms by which cellular diversity is generated. Decades of investigation have shown that a few basic paradigms are used in most organisms and tissue types studied. The process of asymmetric cell division is a primary mechanism for the generation of different cell types (Hawkins and Garriga 1998; Jacobs and Shapiro 1998; Lu et al. 2000). In this process, a precursor cell divides to give rise to daughter cells that differ in their fate or developmental potential from the mother cell or from each other. For instance, in vertebrates, asymmetric division of progenitor neuroblasts gives rise to cortical neurons (Chenn and McConnell 1995; Zhong et al. 1996). In Caenorhabditis elegans, during embryogenesis a sequential series of asymmetric divisions gives rise to the soma and germ-line precursors (Sulston et al. 1983). The mechanisms underlying asymmetric cell division have been intensively studied in the nervous system of Drosophila, and similar principles have been shown to be conserved in other organisms (Lu et al. 2000). These and other studies have shown that a complex and not fully understood interplay between extrinsic polarizing signals and intrinsic lineage-dependent factors results in the adoption of different fates by the two daughter cells.

\footnotetext{
${ }^{1}$ Corresponding author.

E-MAIL sengupta@brandeis.edu; FAX (781) 736-3107.

Article and publication date are at www.genesdev.org/cgi/doi/10.1101/ $\operatorname{gad} .832300$.
}

The generation of cellular diversity is especially critical in the nervous system, which consists of neurons of many different subtypes. Neurons differ from each other in their morphology, connectivity, and function, and this diversity is crucial for the overall function and behavior of the animal. This is especially apparent in the olfactory system. The olfactory sensory system of vertebrates and invertebrates consists of many different types of olfactory neurons, each defined by its unique sensory properties. The nematode C. elegans responds to chemicals using 32 chemosensory neurons of 14 types. These include three olfactory neuron types that sense volatile chemicals (AWA, AWB, and AWC), chemosensory neurons that sense aqueous compounds (primarily ASE, with minor contributions from additional neurons including ASG), and a neuron type that senses ambient temperature (AFD) (Bargmann and Mori 1997; Prasad and Reed 1999; Troemel 1999, and references therein). Neuron types are defined by expression of different sets of signaling genes such as those encoding olfactory receptors, channels, and G proteins (Prasad and Reed 1999; Troemel 1999). Each of these neurons also exhibits a characteristic ciliary and axonal morphology and has different postsynaptic partners (Ward et al. 1975; Ware et al. 1975; Perkins et al. 1986; White et al. 1986). This diversity of function allows C. elegans to sense its complex chemical environment.

How are the sensory identities of each chemosensory neuron defined? In flies, the acj6-encoded POU domain 
transcription factor regulates the sensory functions of a subset of olfactory neurons, partly by regulating the expression of olfactory receptor genes (Clyne et al. $1999 a, b)$. Genes required to regulate the sensory identities of specific chemosensory neuron types have also been identified in C. elegans. These include the homeodomain protein UNC-42 (Baran et al. 1999) and the LIM homeodomain proteins CEH-14 (Cassata et al. 2000) and LIM-6 (Hobert et al. 1999). Interestingly, it has been shown that the three olfactory neuron types-AWA, AWB, and AWC-share a common developmental basal state. In animals mutant for the LIM homeodomain gene lim-4, the AWB neurons lose their identity and adopt the fate of the lineally unrelated, but functionally related AWC olfactory neurons (Sagasti et al. 1999). LIM-4 is required to repress the basal AWC fate and to promote the AWB fate in the AWB neurons. The nuclear hormone receptor ODR-7 plays a similar role in the AWA olfactory neurons, such that in odr-7 mutants, the AWA neurons lose AWA-specific characteristics and adopt AWCspecific identity (Sengupta et al. 1994; Sagasti et al. 1999). Thus, the basal AWC-like olfactory identity of the AWA and AWB neurons is modified by the ODR-7 and LIM-4 proteins to result in the generation of three distinct types of olfactory neurons.

The unexpected finding that AWC is the default fate of the lineally unrelated AWA and AWB olfactory neurons raises several questions regarding the mechanisms by which distinct chemosensory neurons are generated in C. elegans. For instance, it is unknown whether the AWC fate is the default fate of all chemosensory neuron types, or only of the three functionally related olfactory neurons. In either case, since chemosensory neurons arise at distinct locations in the embryo at different times, and are only distantly related by ancestry (Sulston et al. 1983), the role of lineage in their generation is unclear. Cell lineage has been shown to be tightly coupled to specification of cell identity for other cell types, including mechanosensory neurons in C. elegans (Finney and Ruvkun 1990). Several chemosensory neurons arise as sister cells of an asymmetric cell division of a precursor (Sulston et al. 1983). For example, asymmetric cell division gives rise to the distinctly different AWA and ASG chemosensory neurons. Are the distinct identities of these neurons generated through a lineal mechanism, through cell-cell or cell-environment interactions, or through both?

In this study, we have investigated the mechanisms by which the identities of the AWA and ASG lineal sister neurons are defined. We have identified a forkhead domain transcription factor, unc-130, which may act in the AWA/ASG precursors to regulate their asymmetric division and, consequently, the fates of the daughter cells. In unc-130 mutants, the ASG neurons adopt the fate of their AWA sisters. We show that the underlying default developmental state of the ASG chemosensory neurons may be AWC-like, and that the repression of AWA fate and promotion of ASG fate mediated by UNC-130 allows the ASG neurons to adopt their distinct sensory identities. These results suggest that chemosensory neurons in
C. elegans may share a common developmental potential, which is then further restricted in a combinatorial fashion by the action of lineage-specific factors, resulting in the generation of functionally diverse chemosensory neuron types.

\section{Results}

odr-7 is expressed ectopically in unc-130 mutants

The gene odr-7 has previously been shown to be required for the functional specification of the bilaterally symmetric AWA olfactory neurons (Sengupta et al. 1994; Sagasti et al. 1999). We took advantage of the AWA-specific expression of an odr-7::GFP fusion gene to screen for mutants with altered expression of odr-7 (see Materials and Methods). Such mutants would be expected to have defects in the promotion or restriction of AWA fate. We isolated a recessive allele, oy 10, in which ectopic expression of the odr-7::GFP transgene is observed in an additional pair of cells (Fig. 1A,B). oy10 is partially penetrant for this phenotype, since at $25^{\circ} \mathrm{C}$, only $\sim 30 \%$ of oy 10 mutant animals show ectopic expression in an additional cell in at least one side of the animal (Table 1). As shown in Table 1, we also observe occasional, infrequent loss of odr-7 expression. To confirm ectopic expression of odr-7, we generated polyclonal antibodies against ODR-7 (P. Sengupta, unpubl.). Wild-type animals stained with ODR-7 antibodies show nuclear localization of the ODR-7 protein in the AWA neurons (Fig. 1C). oy10 mutants stained with ODR-7 antibodies clearly show ectopic expression of ODR-7 (Fig. 1D; Table 1), confirming the expression pattern observed using the odr-7::GFP fusion gene.

oy10 was found to be allelic to the gene unc-130 (Nash et al. 2000). We examined expression of odr-7 in a predicted null allele of this gene, ev505 (generous gift of B. Nash and J. Culotti, Mount Sinai Hospital, Toronto, Canada; see below). Interestingly, we found that although the penetrance of the mutant phenotype is increased in unc-130(ev505) mutants $166 \%$ of animals
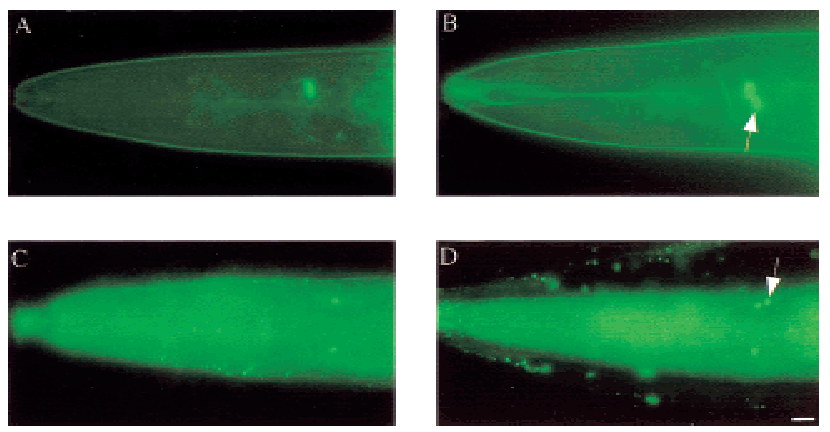

Figure 1. Ectopic expression of odr-7 in unc-130(oy10) mutants. $(A, B)$ Expression of odr-7::GFP in wild-type $(A)$ or unc130(oy10) mutants $(B)$ lateral view. $(C, D)$ Wild type $(C)$ or unc130(oy10) mutants $(D)$ stained with ODR-7 antibodies (top down view). Ectopically expressing cells are marked with an arrow. Anterior is at left. Scale, $10 \mu \mathrm{m}$. 
Table 1. AWA-specific genes are ectopically expressed in unc-130 mutants

\begin{tabular}{|c|c|c|c|c|c|c|c|}
\hline \multirow[b]{2}{*}{ Strain } & & \multicolumn{6}{|c|}{$\%$ of animals with expression pattern: } \\
\hline & $n$ & ฮ & & & & & \\
\hline odr-7::GFP & 116 & 100 & 0 & 0 & 0 & 0 & 0 \\
\hline unc-130(oy10); odr-7::GFP & 1281 & 66.0 & 26.9 & 3.0 & 0.3 & 3.7 & 0.1 \\
\hline unc130(ev505); odr-7::GFP & 210 & 23.3 & 46.2 & 15.7 & 3.8 & 10.5 & 0.5 \\
\hline Wild-type (ODR-7 Ab) & 353 & 100 & 0 & 0 & 0 & 0 & 0 \\
\hline unc-130(oy10) (ODR-7 Ab) & 333 & 61.3 & 30.3 & 3.0 & 1.5 & 3.9 & 0 \\
\hline unc-130(ev505) (ODR-7 Ab) & 318 & 27.0 & 40.3 & 17.9 & 6.6 & 6.9 & 1.3 \\
\hline odr-10::GFP & 212 & 100 & 0 & 0 & 0 & 0 & 0 \\
\hline unc-130(ev505) odr-10::GFP & 117 & 29.1 & 36.8 & 20.5 & 5.1 & 8.5 & 0 \\
\hline gpa-5::GFP & 158 & 100 & 0 & 0 & 0 & 0 & 0 \\
\hline unc-130(ev505); gpa-5::GFP & 114 & 36.0 & 37.7 & 8.8 & 2.6 & 14.0 & 0.9 \\
\hline
\end{tabular}

show ectopic expression of odr-7 on at least one side), it is still incomplete (Table 1). Surprisingly, both alleles show a mildly temperature-sensitive phenotype, indicating a defect in an underlying temperature-sensitive process (Table 2). The temperature sensitivity is manifested in animals grown at $20^{\circ} \mathrm{C}$ compared to $15^{\circ} \mathrm{C}$, but there appears to be little further effect in animals grown at $25^{\circ} \mathrm{C}$. unc-130 mutants exhibit a number of other pleiotropies, including uncoordinated locomotion and defects in cell migration, axon guidance, and male tail development (Nash et al. 2000).

The ectopic ODR-7-expressing cells adopt an AWA-like fate

ODR-7 has been shown to regulate the expression of AWA-specific signaling genes, such as the olfactory receptor odr-10 (Sengupta et al. 1996). In order to determine the extent to which the ectopic odr-7-expressing cells have adopted an AWA-like fate, we examined the expression of genes such as odr-10 and gpa-5 (encoding a G protein subunit; Jansen et al. 1999) known to be expressed in the AWA neurons. As shown in Table 1, both these genes are expressed ectopically to a similar extent

Table 2. unc-130 mutants are temperature sensitive

\begin{tabular}{lccc}
\hline & \multicolumn{3}{c}{$\begin{array}{c}\text { Animals with abnormal odr-7 } \\
\text { expression at temperature }(\%)^{\mathrm{a}}\end{array}$} \\
\cline { 2 - 4 } & $15^{\circ} \mathrm{C}$ & $20^{\circ} \mathrm{C}$ & $25^{\circ} \mathrm{C}$ \\
\hline odr-7::GFP & 0 & 0 & 0 \\
unc-130 (oy10); odr-7::GFP & 18.1 & 44.4 & 40.2 \\
unc-130 (ev505); odr-7::GFP & 51.0 & 71.9 & 78.5
\end{tabular}

${ }^{a}$ This category includes animals showing loss of odr-7 expression as well as animals showing ectopic odr-7 expression. $n>$ 100 in all cases. as odr-7 in unc-130(ev505) animals. We further examined colocalization of ODR-7 and ODR-10 expression in unc-130 mutants and found that in all animals examined, ODR-10 and ODR-7 colocalize in the AWA neurons, as well as in the ectopically expressing cells (Fig. 2A-C).

The AWA neurons have unique ciliary morphology, axonal trajectory, and sensory functions (Perkins et al. 1986; White et al. 1986). We determined whether the ectopic cells have adopted these characteristics in addition to expressing AWA-specific signaling genes. We find that the ciliary morphologies and axonal trajectories of these ectopic cells are generally indistinguishable from those of wild-type AWA neurons (Fig. 2D,E), suggesting that all these aspects of AWA fate have been adopted by the ectopic cells. However, we were unable to examine the sensory functions mediated by these ectopic cells, because of the uncoordinated locomotion exhibited by unc-130 mutants. These results suggest that in unc-130 mutants, one or both of an additional pair of cells adopt an AWA-like fate.

The ASG lineal sisters of the AWA neurons adopt an $A W A$-like fate in unc-130 mutants

We investigated the source of the ectopic AWA-like neurons in unc-130 mutants. In principle, these ectopic neurons could arise through multiple mechanisms, such as reiterated cell lineages or conversion of lineally related or unrelated cell types to an AWA-like fate. In C. elegans, the positions of cells are relatively invariant from animal to animal (Sulston et al. 1983). The relative position of the ectopic AWA-like cells suggested the possibility that in unc-130 mutants, the ASG chemosensory neurons are adopting an AWA-like fate. During development, the ASG and AWA sensory neurons are lineal sisters, arising from terminal division of the $\mathrm{ABp}(1 / \mathrm{r})$ aapapa 

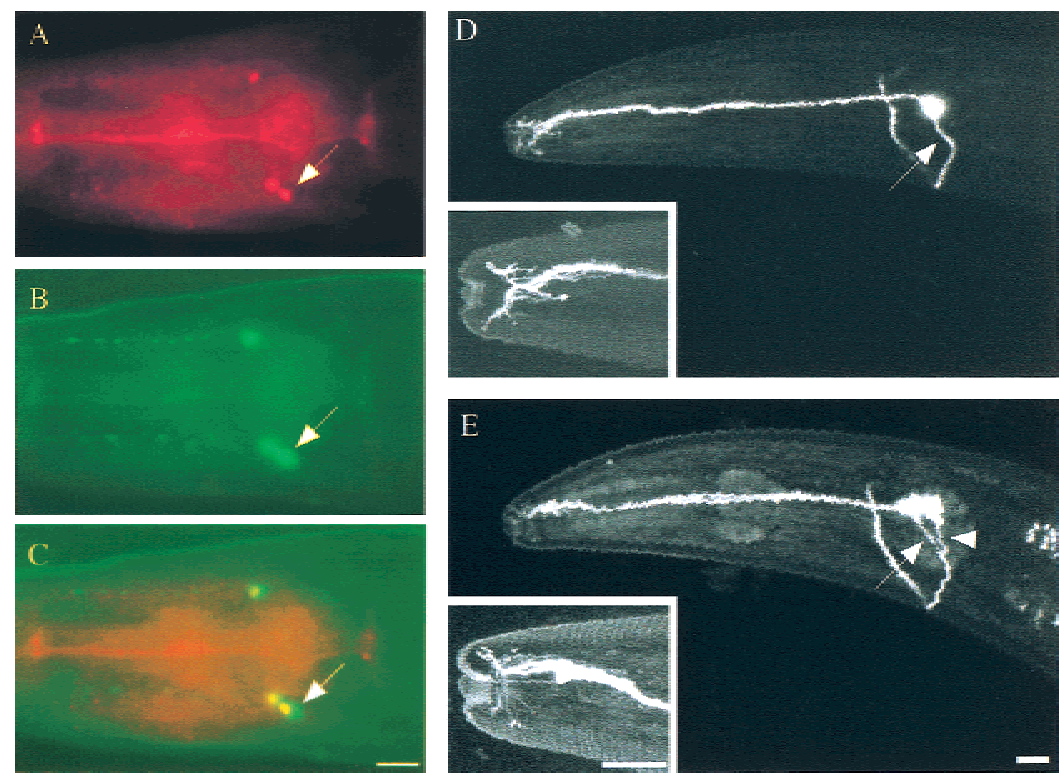

Figure 2. The ectopic cell adopts AWA-like characteristics in unc-130 mutants. (A) Ectopic expression of ODR-7 in unc-130(ev505) mutants carrying an integrated array of odr-10::GFP. ODR-7 is visualized using rhodamine-conjugated secondary antibodies. $(B)$ Ectopic expression of $o d r-10:$ :GFP. $(C)$ Merge of images in $(A)$ and $(B)$ showing colocalization of ODR-7 and ODR-10 in yellow. The ectopic cell is marked with an arrow. $(D, E)$ The cilia and axonal trajectories of the ectopic cell are similar to that of AWA. Confocal image of odr-10::GFP expressing neurons in a wild-type animal $(D)$ or unc-130(ev505) mutant $(E)$. Arrow points to the axon of the wild-type neuron. Note that in $E$, the axon of the ectopic cell (marked with an arrowhead) closely follows the trajectory of the wild-type neuron. (Insets) The branched cilia of an AWA neuron in wild type $(D)$ or unc-130(ev505) mutants $(E)$. The ciliary morphology of the ectopic neuron is indistinguishable from that of the wild-type neuron. Anteror is at left in all images. Scale, $10 \mu \mathrm{m}$. parent cells (Fig. 3A). However, owing to some degree of disorganization in cell body positions in the heads of unc-130 mutants (data not shown), it was difficult to identify the ASG neurons unambiguously. Therefore, we used ASG-specific markers to determine the fate of the ASG neurons in unc-130 mutants. In the simplest model, adoption of AWA-like characteristics by the ASG neurons would be concomitant with loss of ASG-specific gene expression.

A
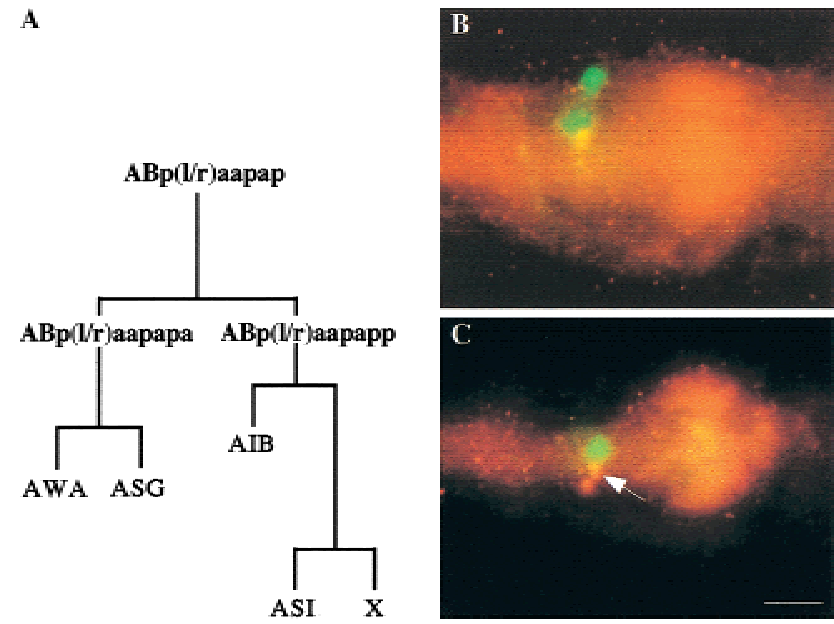

Figure 3. The ASG lineal sisters of the AWA neurons adopt an AWA-like fate in unc-130 mutants. (A) Sublineage giving rise to the AWA and ASG neurons. $(B, C)$ Adoption of AWA-specific gene expression is concomitant with loss of ASG-specific gene expression. (B) One side of an unc-130(ev505) mutant carrying an ops-1::GFP fusion gene. AWA is visualized using ODR-7 antibodies (red); ASG and ADL are visualized through ops-1::GFP expression (green). (C) Other side of the same animal. ODR-7 is ectopically expressed on this side (marked with an arrow). ops$1::$ GFP is expressed in only one cell (tentatively identified as ADL). Anterior is at left. Scale, $10 \mu \mathrm{m}$.
We first examined the expression of an ops-1::GFP fusion gene that is expressed strongly and consistently in the ASG neurons and more variably in the ADL neurons (O. Hobert, pers. comm.). Thus, in wild-type animals carrying integrated copies of the ops-1::GFP fusion gene, either one (ASG) or two (ASG and ADL) cells per side express GFP (data not shown). If there is loss of ASGspecific gene expression upon ectopic expression of AWA-specific genes, then we would expect to see ops$1::$ GFP expression in none or only one (ADL) cell per side, but would not observe GFP expression in two cells. We found that in unc-130(ev505) mutants showing the wild-type pattern of odr-7 expression, $59 \%$ of the animals show ops-1::GFP expression in two neurons per side ( $n=68$ sides; Fig. 3B). In contrast, in unc-130(ev505) animals in which odr-7 is expressed ectopically, we never observe two neurons expressing GFP $(n=75$ sides; Fig. 3C). We tentatively identified the neurons that continue to express GFP in these animals as ADL.

We also examined the expression of an unc-30::GFP fusion gene that is expressed in the ASG neurons, as well as in GABAergic motor neurons in the ventral nerve cord of the animal (Jin et al. 1994). We generated two independent extrachromosomal arrays bearing the unc30::GFP fusion gene in wild-type animals and confirmed mosaic expression in the ASG neurons. We then crossed these arrays into unc-130(ev505) mutants and examined expression in the ASG neurons.

As shown in Table 3, expression in at least one of the two ASG neurons was observed in $\sim 50 \%$ of transgenic wild-type animals. In contrast, expression in the ASG neurons was dramatically reduced or absent in transgenic unc-130 mutants (only $\sim 8 \%-12 \%$ express in at least one ASG neuron). Expression in the ventral nerve cord appears largely unaffected. This loss of expression is not caused by a change in the nature of the arrays, since expression in the ASG neurons is restored upon reintroduction of the arrays from the unc-130 mutants into 
Table 3. Expression of an ASG marker is lost in unc-130 (ev505) mutants

\begin{tabular}{|c|c|c|c|c|}
\hline \multirow[b]{2}{*}{ Strain } & \multicolumn{3}{|c|}{$\begin{array}{c}\text { Percent } \\
\text { transformants with: }\end{array}$} & \multirow[b]{2}{*}{$n$} \\
\hline & $\begin{array}{c}0 \\
\text { ASG }\end{array}$ & $\stackrel{1}{\text { ASG }}$ & $\stackrel{2}{\text { ASG }}$ & \\
\hline \multicolumn{5}{|l|}{ Ex [unc-30::GFP] Array 1 in } \\
\hline $\begin{array}{l}\text { Wild type } \\
\text { unc-130 (ev505) }\end{array}$ & $\begin{array}{l}47.6 \\
91.9\end{array}$ & $\begin{array}{r}27.6 \\
7.2\end{array}$ & $\begin{array}{r}24.8 \\
0.9\end{array}$ & $\begin{array}{l}105 \\
111\end{array}$ \\
\hline $\begin{array}{l}\text { Crossed back into wild type } \\
\text { unc-130 (ev505); odr-7 (ky4) }\end{array}$ & 40.0 & 25.0 & 34.5 & 200 \\
\hline lin-2 (e1309) & 87.8 & 12.2 & 0 & 74 \\
\hline \multicolumn{5}{|l|}{ Ex [unc-30::GFP] Array 2 in } \\
\hline $\begin{array}{l}\text { Wild type } \\
\text { unc-130 (ev505) }\end{array}$ & $\begin{array}{l}47.0 \\
88.3\end{array}$ & $\begin{array}{l}29.1 \\
11.7\end{array}$ & $\begin{array}{c}23.9 \\
0\end{array}$ & $\begin{array}{l}117 \\
111\end{array}$ \\
\hline \multirow[t]{2}{*}{ Crossed back into wild type } & 22.7 & 31.8 & 45.5 & 154 \\
\hline & $\begin{array}{c}0 \\
\mathrm{AWB}\end{array}$ & $\begin{array}{c}1 \\
\mathrm{AWB}\end{array}$ & $\begin{array}{c}2 \\
\mathrm{AWB}\end{array}$ & $n$ \\
\hline \multicolumn{5}{|l|}{ Ex [str-1::GFP] Array in } \\
\hline unc-130 (ev505) & 1.6 & 11.2 & 87.2 & 125 \\
\hline $\begin{array}{l}\text { Crossed back into wild type } \\
\text { unc-130 (ev505) odr-7 (ky4) }\end{array}$ & 1.2 & 12.7 & 86.1 & 165 \\
\hline $\operatorname{lin}-2\left(\right.$ e1309) ${ }^{\mathrm{c}}$ & 0 & 6.3 & 85.4 & 48 \\
\hline
\end{tabular}

${ }^{a}$ One animal expressed unc-30::GFP in two ASG neurons and another unidentified neuron.

${ }^{\mathrm{b}}$ One animal expressed str-1::GFP in three cells.

cFour animals expressed str-1::GFP in three cells.

wild-type animals. This reduction in expression is specific to the unc-30::GFP-containing array, since expression from an array containing a str-1::GFP fusion gene (expressed in the AWB olfactory neurons; Sagasti et al. 1999) is unaltered in unc-130 mutants.

Finally, we also examined the expression of a tax2::GFP fusion gene that is expressed in ASG and additional chemosensory neurons (Coburn and Bargmann 1996). In unc-130 mutants, we observed loss of tax2::GFP expression in neurons misexpressing odr-7. These neurons were tentatively identified as the ASG neurons by cell body position relative to other tax2::GFP-expressing cells (data not shown). Ectopic expression of ASG-specific markers was never observed in unc130 mutants. Taken together, these results suggest that in unc-130 mutants, the ASG neurons adopt an AWAlike fate and lose ASG-specific gene expression. Therefore, UNC-130 may act to repress AWA fate in the ASG neurons.

\section{unc-130 encodes a forkhead-domain protein}

unc-130 was mapped to LG II and localized to a small genetic interval using data from three-factor mapping crosses, complementation experiments with deficiencies, and mapping with respect to identified polymorphisms (Fig. 4A). We obtained rescue of the mutant phenotype of ectopic odr-7 expression with the single cosmid C47G2 in this interval. The rescuing activity was narrowed to a single open reading frame, which encodes a predicted forkhead or winged helix domain transcription factor of 333 amino acids (Fig. 4A,B). Rescue was abolished when the coding sequence was disrupted by insertion of GFP coding sequences (data not shown). The predicted exon/intron boundaries were confirmed by comparison with the sequence of a cDNA isolated by Y. Kohara and the C. elegans EST project. This cDNA likely contains all coding sequences of unc-130 because there is an in-frame stop codon 12 base pairs upstream of the predicted initiator Met.

Forkhead domain proteins have been implicated in numerous developmental and signaling pathways in vertebrates and invertebrates (Kaufmann and Knochel 1996). These proteins are characterized by a highly conserved 100-aa winged helix DNA-binding domain consisting of three helices and two wing domains (Clark et al. 1993; Lai et al. 1993). The forkhead domain of UNC-130 is most closely related to the vertebrate Genesis/HFH2 and FREAC-4 and FREAC-5 forkhead proteins (Fig. 4C; Pierrou et al. 1994; Sutton et al. 1996). Genesis is expressed in embryonic stem cells as well as in premigratory and migrating neural crest cells and motor neuron precursors, and has been shown to act as a transcriptional repressor (Sutton et al. 1996; Labosky and Kaestner 1998; Hromas et al. 1999). Domains N- and C-terminal to the forkhead domain of UNC-130 show no significant similarities to other proteins in databases. The UNC-130 protein sequence contains a strong consensus site for phosphorylation by Akt/PKB kinases (RKRSRS in Fig. 4B; Alessi et al. 1996). Akt/PKB kinases have been shown to modulate the activity and subcellular localization of forkhead proteins via phosphorylation (for a recent review, see Kops and Burgering 1999). However, point mutations at this site (S67A and S67D) had no effect on the function or the subcellular localization of UNC-130 (data not shown).

The molecular nature of the mutations in the oy10 and ev505 alleles was determined. The ev505 allele was found to be a deletion of $\sim 1.8 \mathrm{~kb}$ of genomic sequence, resulting in a truncated protein lacking all residues $\mathrm{C}$ terminal to helix 2 of the winged helix domain (Nash et al. 2000; Fig. 4A). Based on the nature of this mutation, this allele is expected to be null (see below). The oy10 allele was found to be a missense mutation, resulting in an R218C substitution in wing domain 2 (Fig. 4B,C). This residue is highly conserved in members of the winged helix domain protein family (Kaufmann and Knochel 1996). Structural analyses have shown that this residue makes crucial base-specific contacts in the minor groove of the DNA-binding site (Clark et al. 1993). The nature of the mutation in the oy10 allele suggests that the resulting mutant protein would bind DNA inefficiently.

\section{UNC-130 is expressed in the AWA/ASG precursors}

We investigated the expression pattern of unc-130 by generating polyclonal antibodies against the first and third exons of the predicted UNC-130 protein. We ex- 


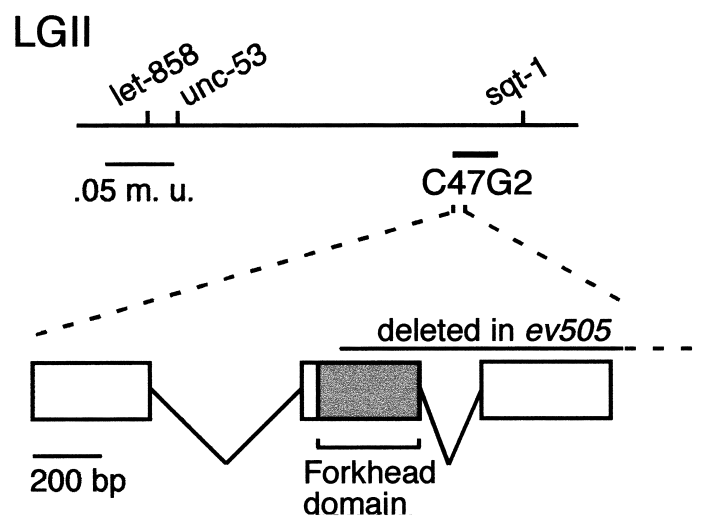

MLFSMESILSSTKPKLEPPPKLEPEVTINEQVVDLPRSNTRLSEPSTSASVLE HDLKFGESRKRSRSLGDEPTEDEDGVPVRKANKRNHSTSSAADSSSDDAKH DDDDDDDSTSRKSMSGHRKSSHAKPPYSYIALIAMSILNSPEKKLTLSEICE

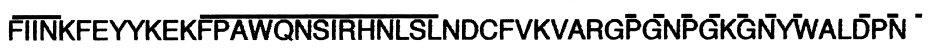

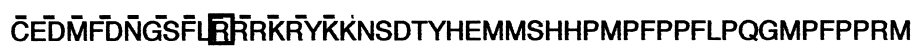
MHPMANIPMLGHPMNPRAVPNMPAFFIPQNIDSQKLLSMMASRIMPMDAP VSSGQKRTSSSSSPNENGSSAVSDKLSA

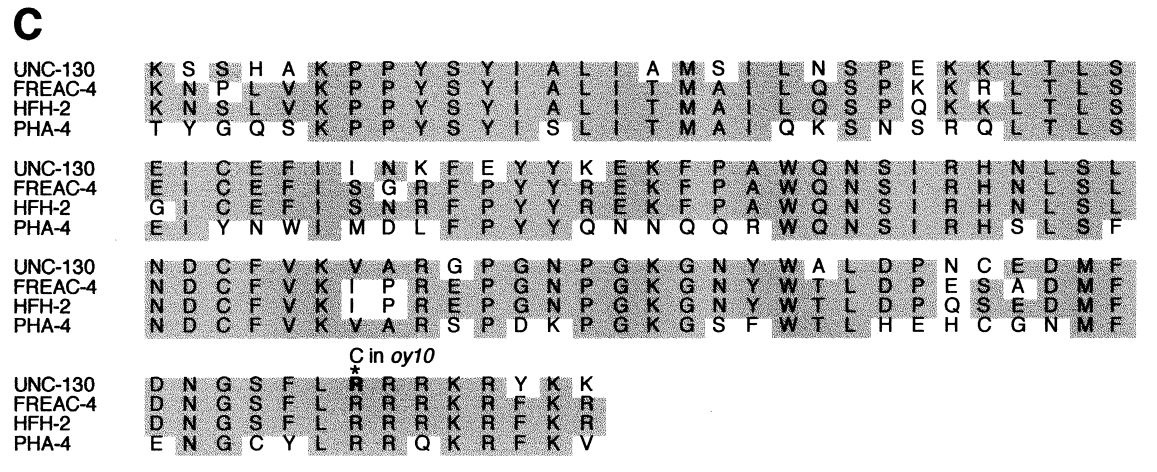

Figure 4. unc-130 encodes a member of the forkhead or winged helix family of transcription factors. $(A)$ Genetic and physical map position of unc-130. unc130 corresponds to the ORF C47G2.2 (C47G2 GenBank accession no. is Z49125). The position of the forkhead domain is indicated in gray. The ev505 deletion is a 1.8 -kb deletion, removing unc-130 coding sequences after residue C155 and breaking $\sim 1.0 \mathrm{~kb}$ downstream from the stop codon. (B) Protein sequence of UNC-130. Residues comprising the predicted helices and wing do
erlines). The residue altered in the oy10 allele is boxed. The consensus site for Akt phosphorylation is in bold. (C) Sequence alignment of the forkhead domain of UNC-130 with the forkhead domains of FREAC-4 (human), HFH-2 (rat), and PHA-4 (C. elegans). Identical residues are shaded. The R to C change in the oy10 allele is marked. See http://www.sciencemag.org/feature/data/985556s7.gif (Ruvkun and Hobert 1998) for a phylogenetic analysis of forkhead domain proteins.

cluded the second exon, which encodes the conserved winged helix domain. We determined that the antibodies were specific for UNC-130 by two criteria. First, no staining was observed in unc-130(ev505) mutants, confirming that this mutation is null (Fig. 5C). Second, we observed UNC-130 staining in expected cell types in animals in which unc-130 was ectopically expressed using different promoters (Fig. 6A; data not shown).

UNC-130 is expressed strongly in embryos and in L1 larvae. Expression is severely reduced or absent in later larval and adult stages. We also found that UNC-130 is localized to the nuclei of all expressing cells (Fig. 5B). Embryonic expression is first observed at about the 60cell stage, when it is expressed in the nuclei of four cells. As embryogenesis continues, UNC-130 becomes more broadly expressed in several cell types. Since the fate of the ASG neurons is affected in unc-130 mutants, we were especially interested in determining whether UNC130 is expressed in the AWA or ASG neurons, or their precursors. The immediate precursors to the AWA and ASG neurons are generated at $\sim 260 \mathrm{~min}$ postfertilization. In order to identify UNC-130-expressing cells at this developmental stage, we double-stained embryos with antibodies against the LIN-26 protein that stain hypodermal cells (Labouesse et al. 1996). As shown in Figure 5B, we found strong UNC-130 expression in the $\mathrm{ABp}(1 / \mathrm{r}) \mathrm{aa}-$ papa cells, which give rise to the AWA and ASG neurons. At this developmental stage, UNC-130 is also expressed in several other neuronal precursors including the $\mathrm{ABp}(1 /$ r)aapapp cells, which are the precursors to the AIB interneurons and the ASI chemosensory neurons (see below). In addition, UNC-130 is expressed in other cell types, including the hypodermal cells hyp4, hyp5, hyp6, hyp7, $\mathrm{HO}$, and $\mathrm{H1}$, as determined by colocalization with LIN26 antibodies.

We wished further to determine if UNC-130 continues to be expressed in the AWA and ASG daughters upon terminal division of the $\mathrm{ABp}(1 / \mathrm{r})$ aapapa cells. AWA and ASG cells are generated at $\sim 300-350$ min postfertilization but are difficult to identify at this stage in the embryo in the absence of markers. Since no appropriate markers are available for these cells at this stage in development, we examined colocalization of UNC-130 with ODR-7 and tax-2::GFP; these markers are expressed well after the respective neurons are born (P. Sengupta, unpubl.; Coburn and Bargmann 1996). In wild-type animals, we failed to observe colocalization of UNC-130 with either of these markers (data not shown). This suggests that either UNC-130 is not expressed in the AWA or ASG daughters or expression is transient. 

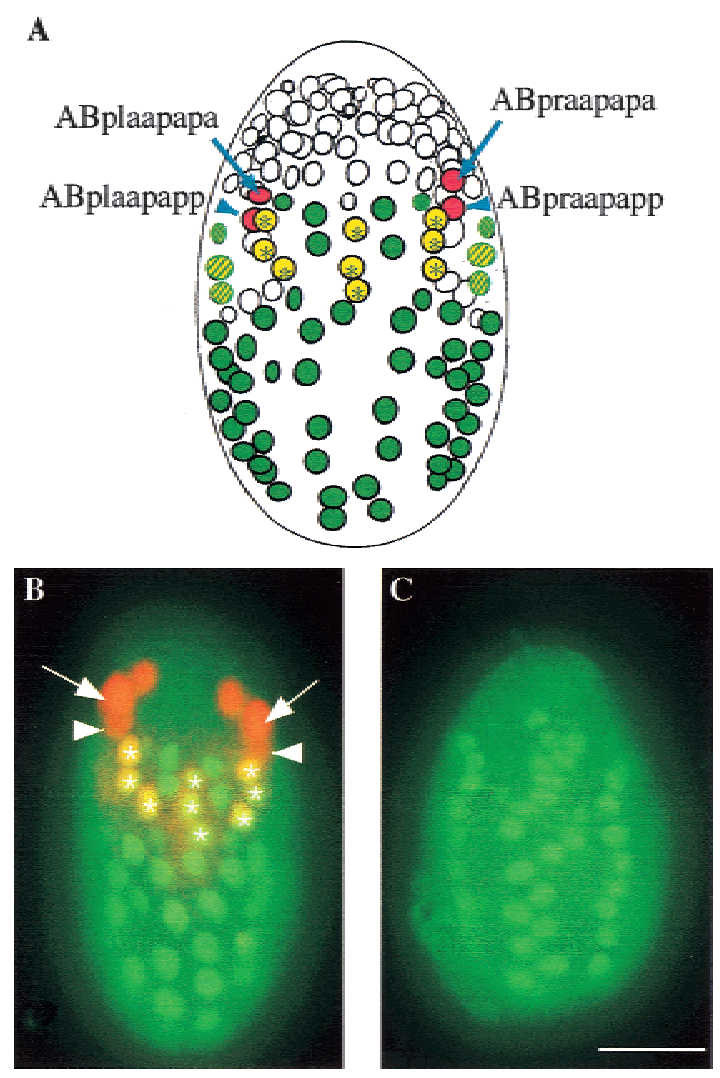

Figure 5. Embryonic expression of UNC-130. (A) Cartoon of a wild-type embryo at approximately 260 min postfertilization (adapted from Sulston et al. 1983). Identified UNC-130-expressing cells are in red. Additional unidentified UNC-130-expressing cells visible in the plane of focus in $B$ are not marked. LIN26-expressing hypodermal cells seen at this developmental stage are in green (Labouesse et al. 1996). Cells in yellow coexpress UNC-130 and LIN-26. Hatched cells also coexpress, but are not visible in the plane of focus in $B . \mathrm{ABp}(1 / \mathrm{r})$ aapapa cells are the precursors to the AWA and ASG neurons, and ABp $(1 / \mathrm{r})$ aapapp cells are the precursors to the ASI neurons (Fig. 3A). (B) Wild-type embryo at the same developmental stage as in $A$ stained with UNC-130 antibodies (red) and LIN-26 antibodies (green). The AWA/ASG precursors are marked with arrows; ASI precursors are marked with an arrowhead. Cells marked with asterisks coexpress UNC-130 and LIN-26. Additional cells not visible in this plane of focus also express UNC-130 at this developmental stage. (C) unc-130(ev505) embryo stained with UNC-130 (red) and LIN-26 antibodies (green). No UNC-130 staining is visible, consistent with the null nature of this allele. Scale, $10 \mu \mathrm{m}$.

unc-130 is necessary to repress AWA fate and promote ASG fate in the ASG neurons

Based on the phenotype of unc-130 mutants and the expression pattern of UNC-130, we propose that UNC-130 functions in the AWA/ASG precursor to repress AWA fate in the ASG neurons, likely through the action of other genes. In the absence of UNC-130 function, the ASG neurons express AWA fate. This suggests that a developmental default state of the ASG neurons is AWAlike, and that this fate must be repressed in order for the
ASG neurons to adopt ASG fate. Is repression of AWA fate in the ASG neurons sufficient for expression of ASG fate? To address this issue, we crossed an unc-30::GFPbearing extrachromosomal array into animals doubly mutant for unc-130(ev505) and odr-7(ky4), and examined expression of unc-30::GFP. Because odr-7 specifies the differentiated fate of the AWA neurons, removal of ODR-7 function in the ASG neurons in unc-130 mutants could allow for the restoration of ASG-specific gene expression. However, as shown in Table 3, we found that the number of animals expressing unc-30 in the ASG neurons in these double-mutant animals is similar to that in unc-130 single mutants. This suggests that ASG fate specification by UNC-130 is not mediated solely through repression of AWA fate, but that UNC-130 must also act to promote ASG fate.

The ASG neurons may adopt an AWC-like fate in unc-130; odr-7 double mutants

The above experiment shows that in unc-130; odr-7 double mutants, the ASG neurons express neither AWA-
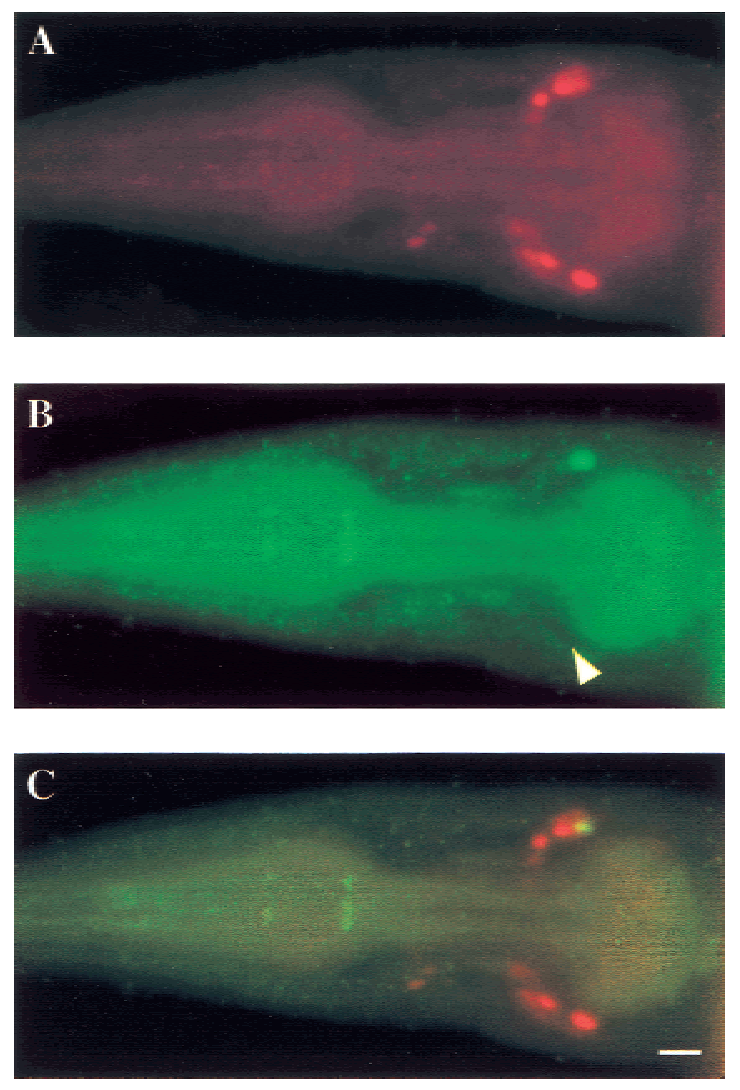

Figure 6. Misexpression of UNC-130 is sufficient to repress ODR-7 expression in the AWA neurons. $(A)$ Ectopic expression of UNC-130 in ciliated neurons of a transgenic animal carrying the osm-6::unc-130 expression construct. Shown is an adult animal stained with UNC-130 antibodies (red). (B) Same animal as in $A$ stained with ODR-7 antibodies (green) showing loss of ODR-7 expression in one AWA neuron (arrowhead). (C) Merge of $A$ and $B$. Anterior is at left; top down view in all panels. Scale, $10 \mu \mathrm{m}$. 
nor ASG-like characteristics. Previous work has shown that the developmental default state of the AWA and AWB olfactory neurons is AWC-like (Sagasti et al. 1999). Genes such as odr-7 and lim-4 act in the AWA and AWB olfactory neurons, respectively, to repress AWC fate and to direct the expression of the appropriate cell fate characteristics. Our experiments suggest that UNC-130 acts similarly to repress AWA fate and to promote ASG characteristics in the ASG neurons. Because the default state of the ASG neurons appears to be AWA-like and the default state of the AWA neurons is AWC-like, we wished to determine whether the ASG neurons can express AWC fate in unc-130(ev505); odr-7(ky4) mutants. We examined unc-130; odr-7 double mutant animals expressing the str-2:: GFP fusion gene as a marker for AWC fate. As previously reported and as shown in Table 4, str-2::GFP is expressed in only one of the two bilaterally symmetric AWC neurons in wild-type animals (Troemel et al. 1999). Owing in part to other pleiotropies, $34 \%$ of unc-130(ev505) animals lack str-2::GFP expression in both AWC neurons (see below). In odr-7 mutants, the AWA neurons can be transformed toward the default AWC fate; we found that $44 \%$ of odr-7(ky4) mutants show str-2::GFP expression in at least two but never more than three neurons (one AWC, and either one or both AWA neurons). However, as shown in Table 4, $\sim 3.3 \%$ of the unc-130; odr-7 double mutants express str$2:: G F P$ in four or more cells. str-2::GFP expression in four or more neurons would be expected to be observed only if AWC is the default state of the ASG neurons (e.g., one AWC, one or two AWA, one or two ASG; other combinations are also possible; see Materials and Methods). The low frequency is consistent with the predicted probability of observing this phenotype (see Materials and Methods). This suggests that the ASG neurons can adopt an AWC-like fate in the absence of UNC-130 and ODR-7 function.

Misexpression of unc-130 in the AWA neurons is sufficient to repress AWA fate but not to promote ASG fate

unc-130 is clearly not sufficient to promote ASG fate, because ASG-specific genes are not expressed in the ad-

Table 4. The ASG neurons can adopt an AWC-like fate in unc-130 (ev505); odr-7 (ky4) double mutants

\begin{tabular}{lcccccc}
\hline & & \multicolumn{5}{c}{$\begin{array}{c}\text { \% expressing str-2::GFP } \\
\text { in total number of cells: }\end{array}$} \\
\cline { 2 - 7 } Strain & $n$ & 0 & 1 & 2 & 3 & $4+$ \\
\hline Wild type & 104 & 1.0 & 99.0 & 0 & 0 & 0 \\
odr-7 (ky4) & 109 & 0 & 56.0 & 33.9 & 10.1 & 0 \\
unc-130 (ev505) & 104 & 33.7 & 66.3 & 0 & 0 & 0 \\
unc-130 (ev505) & & & & & & \\
odr-7 (ky4) & 241 & 10.0 & 32.4 & 37.4 & 17.0 & 3.3 \\
\hline
\end{tabular}

aThese strains also contain unc-9 (e101). See text for details. ditional cell types that arise from UNC-130-expressing precursors. However, since UNC-130 acts to repress AWA fate in the ASG neurons, we wished to determine if expression of unc-130 in the AWA neurons would be sufficient to repress AWA fate and to promote ASG fate.

We chose to misexpress unc-130 using the osm-6 promoter, which drives expression in all chemosensory neurons including the AWA neurons (Collet et al. 1998). We generated 14 independent transgenic lines carrying an osm-6::unc-130 misexpression construct as an extrachromosomal array. Misexpression of UNC-130 in ciliated chemosensory neurons was confirmed by staining transgenic animals with UNC-130 antibodies (Fig. 6A). We next examined expression of ODR-7 in these animals by staining with ODR-7 antibodies. We found that ODR-7 expression is lost in one or both AWA neurons in transgenic animals from 9 of 14 lines (Fig. 6B,C). On average, $\sim 15 \%$ of transgenic animals from these lines have lost ODR-7 expression in one or both AWA neurons (range $4 \%-49 \% ; n \geq 20$ for each line). In contrast, nontransgenic animals from the same lines consistently showed ODR-7 expression in both AWA neurons. However, we also observed colocalization of UNC-130 expression with ODR-7 expression in transgenic animals (data not shown), indicating that misexpression of unc-130 by the osm-6 promoter in the AWA neurons is not fully sufficient to repress AWA fate. This may result from insufficient levels of UNC-130 expression driven by the osm-6 promoter. In general, we noted a correlation between very high levels of ectopic unc-130 expression and loss of ODR-7 expression. Alternatively, since the osm-6 promoter has been shown to be active well after the time of UNC-130 expression (Collet et al. 1998), it is possible that earlier misexpression of unc-130 in the AWA neurons would be fully sufficient to repress AWA fate.

In order to determine whether misexpression of unc130 in the AWA neurons is sufficient to promote ASG fate, we examined expression of ops-1::GFP in transgenic lines carrying the osm-6::unc-130 misexpression construct. However, we did not observe ectopic expression of ops-1::GFP in transgenic animals expressing high levels of UNC-130 (two independent lines, $n \geq 25$ for each line), suggesting that misexpression of unc-130 is not sufficient to promote ASG fate.

\section{unc-130 mutations affect the ASI sensory neuron} sublineage

In addition to being expressed in the AWA/ASG precursors, UNC-130 is also expressed in the $\mathrm{ABp}(\mathrm{l} / \mathrm{r})$ aapapp cells (Fig. 5A,B). These cells divide to give rise to the AIB interneurons and a posterior daughter that redivides to give rise to the ASI chemosensory neurons and a cell that undergoes programmed cell death (Fig. 3A). We examined the role of unc-130 in this sublineage by examining the expression of the str-3::GFP fusion gene that is expressed specifically in the ASI neurons (Peckol et al. 1999). Interestingly, in unc-130(ev505) mutants, 8\% of the animals express str-3::GFP ectopically in one cell per 
Table 5. The ASI neuron sublineage is affected in unc-130 mutants

\begin{tabular}{|c|c|c|c|c|c|c|}
\hline \multirow[b]{2}{*}{ Strain $^{\mathrm{a}}$} & & \multicolumn{5}{|c|}{$\%$ of animals with expression pattern: } \\
\hline & $\mathrm{n}$ & & & & & \\
\hline str-3::GFP & 186 & 97.3 & 0.5 & 0 & 1.6 & 0.5 \\
\hline unc-130(ev505); str-3::GFP & 247 & 82.6 & 6.9 & 0.8 & 9.3 & 0.4 \\
\hline ced-3(n717); str-3::GFP & 110 & 58.2 & 29.1 & 1.8 & 4.5 & 6.4 \\
\hline unc-130(ev505); ced-3(n717); str-3::GFP & 91 & 58.2 & 31.9 & 6.6 & 3.3 & 0 \\
\hline
\end{tabular}

${ }^{\mathrm{a}}$ These strains contain the markers $d p y-20(e 1282) u n c-30(e 191) \mathrm{IV}$.

side (Table 5). Similar to our observations in the AWA sublineage, we also observed occasional loss of str3::GFP expression. The ectopic ASI-like cell may arise from fate conversion of its sister cell that normally undergoes programmed cell death (Sulston et al. 1983). Disruption of this asymmetric cell division in unc-130 mutants could result in survival of the sister cell and adoption of an ASI-like fate at a low frequency. This hypothesis makes two predictions: (1) That in ced-3 mutant animals where apoptotic cell death is prevented (Yuan and Horvitz 1990), the surviving cell should express str-3::GFP; and (2) that no more than two str3::GFP-expressing cells should be seen per side in unc130; ced-3 double-mutant animals. We examined str-3:: GFP expression in ced-3 mutants and found that $30 \%$ of the animals express str-3 ectopically, suggesting that the surviving sister cell of ASI is capable of adopting ASI-like characteristics (Table 5). In addition, in unc-130; ced-3 double-mutant animals, approximately a similar percentage of animals express str-3 ectopically in two cells (Table 5). We did not observe expression in more than two cells per side, which would be expected if a cell other than the sister cell of ASI were adopting an ASIlike fate in unc-130 mutants. These results indicate that unc-130 plays a role in the generation of asymmetry between ASI and its sister cell similar to its role in the AWA/ASG lineage.

unc-130 mutants show defects in a subset of additional sensory neuron lineages

Given the fairly broad expression pattern of unc-130 in neuronal precursors in the developing embryo, it seemed possible that lineages giving rise to other chemosensory neurons in addition to AWA, ASG, and ASI may also be affected in unc-130 mutants. To investigate this possibility, we used markers specific for different chemosensory neurons and examined their expression in unc-130 mutants (Table 6). We found that genes expressed in the thermosensory AFD neurons are ectopically expressed in $\sim 12 \%$ of animals. It is possible that in these animals, the RMD sister cells of the AFD neurons are adopting an AFD-like fate. We also examined gene expression in the AWC olfactory neurons using the marker str-2::GFP.
str-2::GFP is expressed asymmetrically in either the left or the right AWC neuron (Troemel et al. 1999). We found that $-31 \%$ of unc-130 mutants lacked all str-2 expression (Table 6). It has previously been demonstrated that str-2 expression is modulated by axonal contacts and signaling in the AWC neurons. str-2 expression is lost in mutants with defective axon guidance, whereas expression becomes symmetric in both AWC neurons in signaling mutants such as egl-2(n693gf) (Troemel et al. 1999|. Signaling mutants are epistatic to axon guidance mutants for the expression of str-2::GFP. Since unc-130 mutants exhibit axon guidance defects, the loss of str-2 expression in unc-130 mutants could arise as a consequence of these defects and not from defects in AWC cell fate determination. To circumvent this issue, we examined str-2::GFP expression in unc-130(ev505); egl2(n693gf) double mutants. In these double mutants, $\sim 12 \%$ of animals had lost str-2::GFP expression in one or both neurons, indicating that unc-130 may play a minor role in the specification of AWC cell fate. There is also a low but significant loss of gene expression in the ASH neurons, although expression of genes in the AWB olfac-

Table 6. unc-130 mutants have mild defects in a subset of chemosensory neurons

\begin{tabular}{lcccc}
\hline & & \multicolumn{3}{c}{$\begin{array}{c}\text { Animals with abnormal } \\
\text { expression in (\%) }\end{array}$} \\
\cline { 3 - 5 } Neurons & Marker & $\begin{array}{l}\text { Wild } \\
\text { type }\end{array}$ & $\begin{array}{c}\text { unc-130 } \\
\text { (oy10) }\end{array}$ & $\begin{array}{c}\text { unc-130 } \\
\text { (ev505) }\end{array}$ \\
\hline AWB & str-1::GFP & 3.5 & 1.5 & 0.9 \\
AWC & $s t r-2:: G F P$ & 0.4 & $10.0^{\mathrm{a}}$ & $31.4^{\mathrm{b}}$ \\
& str-2::GFP; & $0^{\mathrm{c}}$ & N.D. & $11.7^{\mathrm{d}}$ \\
AFD & egl-2 (n693gf) & & & \\
ASH & scy-8::GFP & 0 & 0.7 & $12.1^{\mathrm{e}}$ \\
AIY & sta-6::GFP & 0 & N.D. & $14.8^{\mathrm{f}}$ \\
\hline
\end{tabular}

a $7 \%$ show loss of expression: $3 \%$ show ectopic expression.

$\mathrm{b}_{3} 1 \%$ show loss of expression; $0.4 \%$ show ectopic expression.

" Normal" str-2::GFP expression in egl-2 (n693gf) mutants is defined as expression in both AWC neurons.

${ }^{\mathrm{d}} 11 \%$ show loss of expression; $0.7 \%$ show ectopic expression.

${ }^{\mathrm{e}}$ Marker is ectopically expressed.

${ }^{\mathrm{f}}$ Expression of marker is lost.

$n>85$ for each genotype. 
tory neurons and AIY interneurons is unaffected in unc130 mutants. Mutations in unc-130 therefore appear to affect the AWA/ASG lineage to a significantly greater degree than other lineages.

We also observed defects in dendritic and ciliary morphology of sensory neurons in unc-130 mutants, with $5 \%-10 \%$ of worms showing dramatic defects. Dendritic defects include premature termination and aberrant forking, whereas ciliary defects include lack of visible cilia, dendrites that end in a knob-like structure, and abnormally branched cilia (data not shown). Axonal trajectories also show defects. These phenotypes were not characterized in detail. These defects may indicate a broader role for unc-130 in regulating neurite morphology or, alternatively, could arise as secondary defects as a consequence of loss of unc-130 function in other cell types.

\section{Discussion}

unc-130 is required for the generation of asymmetry in the AWA/ASG lineage

Our results show that the forkhead domain protein UNC-130 functions to regulate the asymmetric division that gives rise to the AWA and ASG chemosensory neurons. How might UNC-130 act? Daughter cells arising from the division of a precursor cell can adopt different fates through a combination of intrinsic and extrinsic mechanisms. Intrinsic mechanisms involve the asymmetric localization and segregation of cell fate determinants, resulting in the generation of daughter cells that differ from each other at birth. Extrinsic mechanisms involve the generation of asymmetry in initially symmetric cells, as a result of signaling between the cells or between the cells and the environment. Both types of mechanisms have been described in several organisms (Hawkins and Garriga 1998; Lu et al. 2000). In the central nervous system of Drosophila, determinants such as Numb and Prospero are asymmetrically localized to the basal pole of neuroblasts, and are segregated to only the GMC daughter cells (Rhyu et al. 1994; Hirata et al. 1995; Knoblich et al. 1995; Spana and Doe 1995). Similar asymmetric localization of determinants, and subsequent asymmetric cell division, has been well described in the early embryonic development of C. elegans, as well as in unicellular organisms such as Saccharomyces cerevisiae and Bacillus subtilis (Jacobs and Shapiro 1998; Bowerman and Shelton 1999). Regulation of asymmetry by signaling mechanisms such as the Wnt/wingless pathway has also been characterized (Wodarz and Nusse 1998).

We propose that transcription mediated by UNC-130 is required for the correct expression and/or asymmetric segregation of putative cell fate determinants in the AWA/ASG precursor cells. Defects in the segregation of such determinants could result in the observed ASG cell fate transformation, as well as occasional loss of AWAspecific gene expression. Interestingly, a similar role has been proposed for the Jumeaux forkhead domain protein in Drosophila (Cheah et al. 2000). Jumeaux is required for the correct localization and segregation of Numb in the precursor to the RP2 motor neuron. Homologs of Numb and Prospero have been identified in C. elegans, although their functions in the nervous system have not been elucidated (Ruvkun and Hobert 1998). A novel protein HAM-1 has been described that fulfills the criteria of a cell fate determinant in C. elegans (Guenther and Garriga 1996). HAM-1 is asymmetrically localized in precursor cells and is segregated preferentially to one daughter cell. In ham-1 mutants, asymmetric cell division in several neuronal lineages is affected. Although the AWA/ASG cell division is unaffected in ham-1 mutants (T. Sarafi-Reinach and P. Sengupta, unpubl.), it is possible that UNC-130 regulates the expression or segregation of molecules with functions similar to those of HAM-1 in this lineage. Alternatively, UNC-130 could itself be segregated to one or both daughter cells. We have not observed unc-130 expression in the AWA and ASG neurons after birth; however, unc-130 could be expressed transiently in one or both of these cells.

Winged helix or forkhead proteins have been shown to act as both transcriptional activators and repressors. The murine forkhead protein Genesis appears to act primarily as a transcriptional repressor, as do the XBF proteins in Xenopus (Sutton et al. 1996; Bourguignon et al. 1998; Mariani and Harland 1998). Interestingly, Genesis, like UNC-130 and Jumu, is expressed in neuronal progenitors (Labosky and Kaestner 1998). In C. elegans, the forkhead protein LIN-31 is thought to act as either a repressor or an activator, depending on its phosphorylation status and interaction with the ETS domain protein LIN-1 (Tan et al. 1998). UNC-130 could activate a repressor of AWA cell fate in the precursor cells, which is then segregated to the ASG neurons. We have shown that UNC-130 also acts to promote ASG fate. It is possible that different functions of UNC-130 are mediated via interaction with different proteins, or by its phosphorylation state. We note that the protein sequence of UNC-130 contains two predicted MAP kinase phosphorylation sites, as well as a serine-rich domain at its $\mathrm{C}$ terminus, which could be a target for phosphorylation. Forkhead proteins have been shown to interact with ETS domain proteins as well as SMAD proteins (Chen et al. 1996, 1997; Tan et al. 1998). Since the unc-130(ev505) putative null allele is incompletely penetrant for the AWA/ASG defect, it is likely that UNC-130 acts partly redundantly with other gene products. These proteins could act together with UNC-130, or could act in an independent pathway.

Taken together, we propose that UNC-130 acts together with other proteins in the precursor cells or in the ASG neurons to activate ASG cell fate determinants, and to repress AWA cell fate. A goal for the future is to identify targets of UNC-130 regulation. These are expected to be different sets of genes in different lineages, since unc-130 appears to act in many developmental processes in several cell types (Nash et al. 2000). For example, it has been found that unc-129, which encodes a TGF- $\beta$ 
ligand, is a target of repression by UNC-130 in muscle cells (Nash et al. 2000); however, we have found that mutations in unc-129 have no effect on the AWA/ASG cell fate decision (T. Sarafi-Reinach and P. Sengupta, unpubl.).

\section{A hierarchical model of chemosensory neuron fate determination}

Previous work has suggested that the AWC fate is the default developmental fate of olfactory neurons in C. elegans (Sagasti et al. 1999). Expression of genes such as odr-7 and lim-4 modifies this fate to result in the generation of the three types of olfactory neurons. Results presented here suggest that the AWC fate may be the default fate of other chemosensory neurons in addition to the olfactory neurons. In unc-130; odr-7 double mutants, the ASG neurons appear to exhibit AWC-like characteristics, such as expression of the AWC-specific str-2 marker. We suggest that the AWC fate may be the default fate of most, if not all, chemosensory neurons. These chemosensory neurons could be related by overall function, or possibly by inclusion in a particular sense organ. Chemosensory neurons in the head are part of the amphid sense organ. Organ identity genes have been previously defined such as the C. elegans winged helix gene pha-4, which is required for the expression of pharyngeal organ identity (Horner et al. 1998; Kalb et al. 1998). Amphid organ identity genes could function through the lineage or through the action of extracellular signals to induce the basal AWC fate in all cells that will form this organ. Alternatively, a common chemosensory neuron determinant could be induced in all chemosensory cell types, including chemosensory cells in other sense organs.

We propose that diversity of function in the chemosensory nervous system results from layers of identity, generated through the action of transcription factors. The basal layer in both the AWA and ASG neurons could be AWC-like. Expression of ODR-7 generates AWA identity in the AWA neurons. The ASG neurons are also capable of exhibiting AWA identity; however, this fate is repressed by the action of UNC-130, which also acts to promote ASG fate. Similarly, in the case of other chemosensory neurons, expression of genes combinatorially in a lineage-specific manner could layer distinct cell identities. Further cell type-specific differentiated features may be regulated by linear or parallel cascades of additional genes. A major challenge for the future is to identify the genes that act to define the identities and specific functional characteristics of each type of chemosensory neuron.

\section{Materials and methods}

Strains and plasmids

Wild-type worms used were C. elegans variety Bristol, strain N2. Worms were grown using standard methods (Brenner 1974).
Strains were obtained from the Caenorhabditis Genetics Center unless noted otherwise. unc-130(ev505) was a generous gift of B. Nash and J. Culotti (Mount Sinai Hospital, Toronto, Canada). Strains carrying integrated arrays of fusion genes were provided by the following: gpa-5::GFP (G. Jansen); ops-1::GFP and $t$ tx-3::GFP (O. Hobert); tax-2::GFP, str-3::GFP, str-1::GFP, str-2::GFP, and sra-6::GFP (C. Bargmann); gcy-8::GFP (J. Satterlee) (Yu et al. 1997).

The unc-30::GFP fusion construct was provided by Y. Jin; the osm-6 promoter by P. Swoboda; the $g c y-8::$ GFP fusion construct by D. Garbers, and the expression vector pPD95.77 by A. Fire. osm-6::unc-130 was constructed by replacing GFP coding sequences in the osm-6::GFP expression vector with unc-130 coding sequences amplified from the cDNA.

Isolation, mapping, and cloning of unc-130

A strain carrying integrated copies of odr-7::GFP was mutagenized using EMS as the mutagen and standard mutagenesis protocols. $F_{1}$ progeny of mutagenized animals were placed singly on plates, and their $F_{2}$ progeny screened for altered odr7::GFP expression using a Zeiss Axioskop at 40× magnification. The oy10 allele was outcrossed a total of three times prior to characterization. unc-130(oy10) was mapped to LG II and finemapped using standard mapping methods.

A PCR product containing $2.3 \mathrm{~kb}$ of upstream sequences, the unc-130 genomic sequence, and $1.5 \mathrm{~kb}$ of downstream sequences was subcloned into the Topo 2.1 vector (Invitrogen), and was found to rescue the mutant phenotype in 7 of 8 independent transgenic lines examined. unc-130 coding sequences were disrupted by insertion of a PCR product containing GFP coding sequences in the SacII site in the first exon of unc-130. To identify the molecular lesions in unc-130 alleles, the genomic coding sequence of unc-130 was amplified by PCR from the oy 10 and ev505 mutants in three independent reactions each, and the products directly sequenced.

\section{Germ line transformations}

Germ line transformations were carried out using standard protocols (Mello and Fire 1995). Coinjection markers used were the dominant pRF4 rol-6(su1006) marker at $100 \mathrm{ng} / \mathrm{\mu L}$ and the ofm$1::$ GFP construct, which expresses GFP in coelomocytes at 50

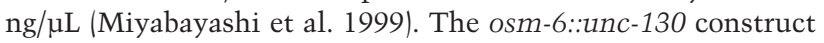
was injected at 30 or $60 \mathrm{ng} / \mathrm{\mu L}$; all other constructs were injected at $30 \mathrm{ng} / \mu \mathrm{L}$.

\section{Generation of UNC-130 antibodies and immunocytochemistry}

Sequences coding for the first and third exons of unc-130 were fused to GST coding sequences independently, using the vector pGEX-4T-1 (Pharmacia). The two fusion proteins were combined in a 2:1 ratio of Exon 1:Exon 3 and injected into rabbits and rats (Cocalico Biologicals). Affinity-purified polyclonal antibodies were used to stain embryos using a modified method of Chin-Sang et al. (1999). Adults were stained using a modified Finney-Ruvkun protocol (Finney and Ruvkun 1990). Detailed protocols are available upon request.

Affinity-purified UNC-130 antibodies generated in rats were used at 1:10 dilution, LIN-26 antibodies at 1:1000 dilution, and ODR-7 antibodies generated in rabbits were used at 1:20 dilution. Secondary antibodies used were the following: Rhodamine-conjugated donkey anti-rat and anti-rabbit antibodies 
(Jackson Biologicals) and fluorescein-conjugated goat anti-rabbit antibodies (Cappel). Secondary antibodies were used at a 1:25 dilution.

\section{Microscopy}

Where applicable, animals were examined by epifluorescence, and images were captured using a CCD digital camera (Hamamatsu) and PCI digital frame grabber. Images were pseudocolored and analyzed using Openlab (Improvision) and Adobe Photoshop software. Confocal images were generated by stacking of optical Z sections obtained using a BioRad MRC600 confocal microscope.

\section{Expression of str-2::GFP in unc-130(ev505); odr-7(ky4) mutants}

We calculated the probability of observing str-2::GFP expression in the ASG neurons in unc-130; odr-7 double mutants as follows. In wild-type animals, we expect to see one cell per animal (AWC) expressing str-2::GFP. In odr-7(ky4) mutants, we expect to see one (AWC), two (one AWC and one AWA), or three (one AWC, two AWA) cells expressing GFP. In unc-130 mutants, we observed either zero or one (AWC) cell expressing GFP. If ASG reverts to an AWC-like default state in unc-130; odr-7 double mutants, then in addition to a total of zero, one, two, or three GFP-expressing cells, we would also expect to observe the following patterns of GFP expression, which are not observed in either wild-type or single mutant animals: (1) Three GFP-expressing cells (AWC, AWA, and ASG) on one side and zero on the other (total of three cells); (2) three GFP-expressing cells (AWC, AWA, and ASG) on one side and one (AWA or ASG) on the other (total of four cells); (3) three GFP-expressing cells (AWC, AWA, and ASG) on one side and two (AWA and ASG) on the other (total of five cells); and (4) two GFP-expressing cells on each side (AWC and AWA, or AWC and ASG, or AWA and ASG; with GFP being expressed in only one AWC neuron on one side) (total of four cells). The calculated probabilities (based on the penetrance of str-2::GFP expression in each of the single mutants) and observed numbers of animals in each of the above categories in unc-130; odr-7 double mutants were the following: (1) expected, $0.65 \%$; observed, $0.4 \%$; (2) expected, $0.4 \%$; observed, $1.2 \%$; (3) expected, $0.03 \%$; observed, $0.4 \%$; and $(4)$ expected, $0.9 \%$; observed, $1.7 \%$. These phenotypes were not observed in wild-type or single-mutant animals.

\section{Acknowledgments}

We are grateful to B. Nash and J. Culotti for communication of results prior to publication and for the ev505 allele. We thank O. Hobert for the ops-1::GFP construct; Y. Kohara for unc-130 cDNA clones; A. Fire for plasmids; M. Labouesse for LIN-26 antibodies; The Caenorhabditis Genetics Center for strains; A. Coulson and the Sanger Centre for cosmids; E. Dougherty for assistance with confocal microscopy; and C. Bargmann, S. Birren, K. White, and J. Satterlee for comments on the manuscript. We also thank the Sengupta lab for advice and discussion. T.S-R. was a predoctoral fellow of the Howard Hughes Medical Institute. This work was supported by NIH grant GM56223 to P.S and funds from the Searle Scholar and Packard Foundations.

The publication costs of this article were defrayed in part by payment of page charges. This article must therefore be hereby marked "advertisement" in accordance with 18 USC section 1734 solely to indicate this fact.

\section{References}

Alessi, D.R., Caudwell, F.B., Andjelkovic, M., Hemmings, B.A., and Cohen, P. 1996. Molecular basis for the substrate specificity of protein kinase $\mathrm{B}$; comparison with MAPKAP kinase-1 and p70 S6 kinase. FEBS Lett. 399: 333-338.

Baran, R., Aronoff, R., and Garriga, G. 1999. The C. elegans homeodomain gene unc-42 regulates chemosensory and glutamate receptor expression. Development 126: 2241-2251.

Bargmann, C.I. and Mori, I. 1997. Chemotaxis and thermotaxis. In C. elegans II (ed. D.S. Riddle et al.), pp. 717-737. Cold Spring Harbor Laboratory Press, Cold Spring Harbor, New York.

Bourguignon, C., Li, J., and Papalopulu, N. 1998. XBF-1, a winged helix transcription factor with dual activity, has a role in positioning neurogenesis in Xenopus competent ectoderm. Development 125: 4889-4900.

Bowerman, B. and Shelton, C.A. 1999. Cell polarity in the early Caenorhabditis elegans embryo. Curr. Opin. Genet. Dev. 9: 390-395.

Brenner, S. 1974. The genetics of Caenorhabditis elegans. Genetics 77: 71-94.

Cassata, G., Kagoshima, H., Andachi, Y., Kohara, Y., Durrenberger, M.B., Hall, D.H., and Burglin, T.R. 2000. The LIM homeobox gene ceh-14 confers thermosensory function to the AFD neurons in Caenorhabditis elegans. Neuron 25: 587-597.

Cheah, P.Y., Chia, W., and Yang, X. 2000. Jumeaux, a novel Drosophila winged-helix protein, is required for generating asymmetric sibling neuronal cell fates. Development 127: 3325-3335.

Chen, X., Rubock, M.J., and Whitman, M. 1996. A transcriptional partner for MAD proteins in TGF- $\beta$ signalling. Nature 383: 691-696.

Chen, X., Weisberg, E., Fridmacher, V., Watanabe, M., Naco, G., and Whitman, M. 1997. Smad4 and FAST-1 in the assembly of activin-responsive factor. Nature 389: 85-89.

Chenn, A. and McConnell, S.K. 1995. Cleavage orientation and the asymmetric inheritance of Notch 1 immunoreactivity in mammalian neurogenesis. Cell 82: 631-641.

Chin-Sang, I.D., George, S.E., Ding, M., Moseley, S.L., Lynch, A.S., and Chisholm, A.D. 1999. The ephrin VAB-2/EFN-1 functions in neuronal signaling to regulate epidermal morphogenesis in C. elegans. Cell 99: 781-790.

Clark, K.L., Halay, E.D., Lai, E., and Burley, S.K. 1993. Co-crystal structure of the HNF-3/fork head DNA-recognition motif resembles histone H5. Nature 364: 412-420.

Clyne, P.J., Certel, S.J., de Bruyne, M., Zaslavsky, L., Johnson, W.A., and Carlson, J.R. 1999a. The odor specificities of a subset of olfactory receptor neurons are governed by Acj6, a POU-domain transcription factor. Neuron 22: 339-347.

Clyne, P.J., Warr, C.G., Freeman, M.R., Lessing, D., Kim, J., and Carlson, J.R. 1999b. A novel family of divergent seven-transmembrane proteins: Candidate odorant receptors in Drosophila. Neuron 22: 327-338.

Coburn, C. and Bargmann, C.I. 1996. A putative cyclic nucleotide-gated channel is required for sensory development and function in C. elegans. Neuron 17: 695-706.

Collet, J., Spike, C.A., Lundquist, E.A., Shaw, J.E., and Herman, R.K. 1998. Analysis of osm-6, a gene that affects sensory cilium structure and sensory neuron function in Caenorhabditis elegans. Genetics 148: 187-200.

Finney, M. and Ruvkun, G. 1990. The unc-86 gene product couples cell lineage and cell identity in C. elegans. Cell 63: 895-905.

Guenther, C. and Garriga, G. 1996. Asymmetric distribution of 
the C. elegans HAM-1 protein in neuroblasts enables daughter cells to adopt distinct fates. Development 122: 35093518.

Hawkins, N. and Garriga., G. 1998. Asymmetric cell division: From A to Z. Genes \& Dev. 12: 3625-3638.

Hirata, J., Nakagoshi, H., Nabeshima, Y., and Matsuzaki, F. 1995. Asymmetric segregation of the homeodomain protein Prospero during Drosophila development. Nature 377: 627630.

Hobert, O., Tessmar, K., and Ruvkun, G. 1999. The Caenorhabditis elegans lim-6 LIM homeobox gene regulates neurite outgrowth and function of particular GABAergic neurons. Development 126: 1547-1562.

Horner, M.A., Quintin, S., Domeier, M.E., Kimble, J., Labouesse, M., and Mango, S.E. 1998. pha-4, an HNF-3 homolog, specifies pharyngeal organ identity in Caenorhabditis elegans. Genes \& Dev. 12: 1947-1952.

Hromas, R., Ye, H., Spinella, M., Dmitrovsky, E., Xu, D., and Costa, R.H. 1999. Genesis, a winged helix transcriptional repressor, has embryonic expression limited to the neural crest, and stimulates proliferation in vitro in a neural development model. Cell Tissue Res. 297: 371-382.

Jacobs, C. and Shapiro, L. 1998. Microbial asymmetric cell division: Localization of cell fate determinants. Curr. Opin. Genet. Dev. 8: 386-391.

Jansen, G., Thijssen, K.L., Werner, P., van der Horst, M., Hazendonk, E., and Plasterk, R.H. 1999. The complete family of genes encoding G proteins of Caenorhabditis elegans. Nat. Genet. 21: 414-419.

Jin, Y., Hoskins, R., and Horvitz, H.R. 1994. Control of type-D GABAergic neuron differentiation by C. elegans UNC-30 homeodomain protein. Nature 372: 780-783.

Kalb, J.M., Lau, K.K., Goszczynski, B., Fukushige, T., Moons, D., Okkema, P.G., and McGhee, J.D. 1998. pha-4 is Ce-fkh-1, a fork head/HNF-3 $\alpha, \beta, \gamma$ homolog that functions in organogenesis of the C. elegans pharynx. Development 125: 21712180.

Kaufmann, E. and Knochel, W. 1996. Five years on the wings of fork head. Mech. Dev. 57: 3-20.

Knoblich, J.A., Jan, L.Y., and Jan, Y.N. 1995. Asymmetric segregation of Numb and Prospero during cell division. Nature 377: 624-627.

Kops, G.J. and Burgering, B.M. 1999. Forkhead transcription factors: New insights into protein kinase B (c-akt) signaling. $J$. Mol. Med. 77: 656-665.

Labosky, P.A. and Kaestner, K.H. 1998. The winged helix transcription factor Hfh2 is expressed in neural crest and spinal cord during mouse development. Mech. Dev. 76: 185-190.

Labouesse, M., Hartwieg, E., and Horvitz, H.R. 1996. The Caenorhabditis elegans LIN-26 protein is required to specify and/or maintain all non-neuronal ectodermal cell fates. Development 122: 2579-2588

Lai, E., Clark, K.L., Burley, S.K., and Darnell, J.E., Jr. 1993. Hepatocyte nuclear factor $3 /$ fork head or winged helix proteins: A family of transcription factors of diverse biologic function. Proc. Natl. Acad. Sci. 90: 10421-10423.

Lu, B., Jan, L., and Jan, Y.-N. 2000. Control of cell divisions in the nervous system: Symmetry and asymmetry. Annu. Rev. Neurosci. 23: 531-556.

Mariani, F.V. and Harland, R.M. 1998. XBF-2 is a transcriptional repressor that converts ectoderm into neural tissue. Development 125: 5019-5031.

Mello, C.C. and Fire, A. 1995. DNA transformation. In Caenorhabditis elegans: Modern biological analysis of an organism (ed. H.F. Epstein and D.C. Shakes), pp. 452-480. Academic Press, San Diego.
Miyabayashi, T., Palfreyman, M.T., Sluder, A.E., Slack, F., and Sengupta, P. 1999. Expression and function of members of a divergent nuclear receptor family in Caenorhabditis elegans. Dev. Biol. 215: 314-331.

Nash, B.N., Zheng, H., Colavita, A., Roy, P.J., and Culotti, J.G. The Forkhead transcription factor UNC-130 is required for the graded spatial expression of the UNC-129 TGF- $\beta$ guidance factor in C. elegans. Genes \& Dev. (this issue).

Peckol, E.L., Zallen, J.A., Yarrow, J.C., and Bargmann, C.I. 1999. Sensory activity affects sensory axon development in C. elegans. Development 126: 1891-1902.

Perkins, L.A., Hedgecock, E.M., Thomson, J.N., and Culotti, J.G. 1986. Mutant sensory cilia in the nematode Caenorhabditis elegans. Dev. Biol. 117: 456-487.

Pierrou, S., Hellqvist, M., Samuelsson, L., Enerback, S., and Carlsson, P. 1994. Cloning and characterization of seven human forkhead proteins: Binding site specificity and DNA bending. EMBO J. 13: 5002-5012.

Prasad, B. and Reed, R.R. 1999. Chemosensation: Molecular mechanisms in worms and mammals. Trends Genet. 15: 150-153.

Rhyu, M.S., Jan, L.Y., and Jan, Y.N. 1994. Asymmetric distribution of Numb protein during division of the sensory organ precursor cell confers distinct fates to daughter cells. Cell 76: 477-491.

Ruvkun, G. and Hobert, O. 1998. The taxonomy of developmental control in Caenorhabditis elegans. Science 282: 2033 2041.

Sagasti, A., Hobert, O., Troemel, E.R., Ruvkun, G., and Bargmann, C.I. 1999. Alternative olfactory neuron fates are specified by the LIM homeobox gene lim-4. Genes \& Dev. 13: 1794-1806.

Sengupta, P., Colbert, H.A., and Bargmann, C.I. 1994. The C. elegans gene odr-7 encodes an olfactory-specific member of the nuclear receptor superfamily. Cell 79: 971-980.

Sengupta, P., Chou, J.H., and Bargmann, C.I. 1996. odr-10 encodes a seven transmembrane domain olfactory receptor required for responses to the odorant diacetyl. Cell 84: 899909.

Spana, E.P. and Doe, C.Q. 1995. The prospero transcription factor is asymmetrically localized to the cell cortex during neuroblast mitosis in Drosophila. Development 121:31873195.

Sulston, J.E., Schierenberg, E., White, J.G., and Thomson, J.N. 1983. The embryonic cell lineage of the nematode Cae norhabditis elegans. Dev. Biol. 100: 64-119.

Sutton, J., Costa, R., Klug, M., Field, L., Xu, D., Largaespada, D.A., Fletcher, C.F., Jenkins, N.A., Copeland, N.G., Klemsz, M., et al. 1996. Genesis, a winged helix transcriptional repressor with expression restricted to embryonic stem cells. J. Biol. Chem. 271: 23126-23133.

Tan, P.B., Lackner, M.R., and Kim, S.K. 1998. MAP kinase signaling specificity mediated by the LIN-1 Ets/LIN-31 WH transcription factor complex during C. elegans vulval induction. Cell 93: 569-580.

Troemel, E.R. 1999. Chemosensory signaling in C. elegans. Bioessays 21: 1011-1020.

Troemel, E.R., Sagasti, A., and Bargmann, C.I. 1999. Lateral signaling mediated by axon contact and calcium entry regulates asymmetric odorant receptor expression in C. elegans. Cell 99: 387-398.

Ward, S., Thomson, N., White, J.G., and Brenner, S. 1975. Electron microscopical reconstruction of the anterior sensory anatomy of the nematode Caenorhabditis elegans. J. Comp. Neurol. 160: 313-337.

Ware, R.W., Clark, D., Crossland, K., and Russell, R.L. 1975. 
The nerve ring of the nematode Caenorhabditis elegans: Sensory input and motor output. I. Comp. Neur. 162: 71110.

White, J.G., Southgate, E., Thomson, J.N., and Brenner, S. 1986. The structure of the nervous system of the nematode Caenorhabditis elegans. Phil. Transact. R. Soc. Lond. B 314: 1340.

Wodarz, A. and Nusse, R. 1998. Mechanisms of Wnt signaling in development. Annu. Rev. Cell Dev. Biol. 14: 59-88.

Yu, S., Avery, L., Baude, E., and Garbers, D.A. 1997. Guanylyl cyclase expression in specific sensory neurons: A new family of chemosensory receptors. Proc. Natl. Acad. Sci. 94: 33843387.

Yuan, J.Y. and Horvitz, H.R. 1990. The Caenorhabditis elegans genes ced-3 and ced-4 act cell autonomously to cause programmed cell death. Dev. Biol. 138: 33-41.

Zhong, W., Feder, J.N., Jiang, M.M., Jan, L.Y., and Jan, Y.N. 1996. Asymmetric localization of a mammalian numb homolog during mouse cortical neurogenesis. Neuron 17: 4353. 


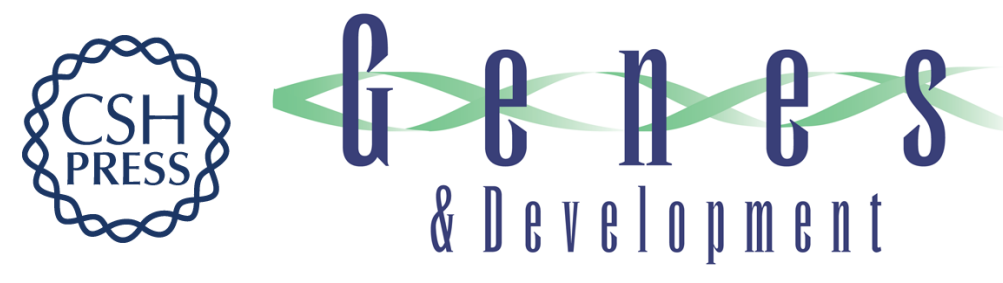

\section{The forkhead domain gene unc-130 generates chemosensory neuron diversity in C. elegans}

Trina R. Sarafi-Reinach and Piali Sengupta

Genes Dev. 2000, 14:

Access the most recent version at doi:10.1101/gad.832300

References This article cites 57 articles, 19 of which can be accessed free at: http://genesdev.cshlp.org/content/14/19/2472.full.html\#ref-list-1

License

Email Alerting

Receive free email alerts when new articles cite this article - sign up in the box at the top Service right corner of the article or click here.

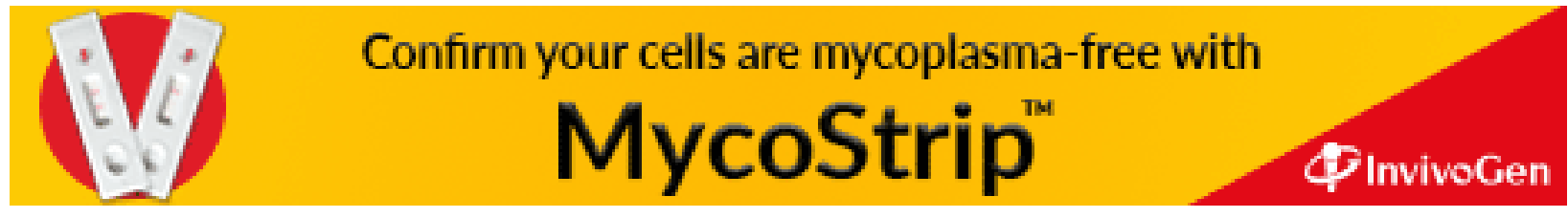

